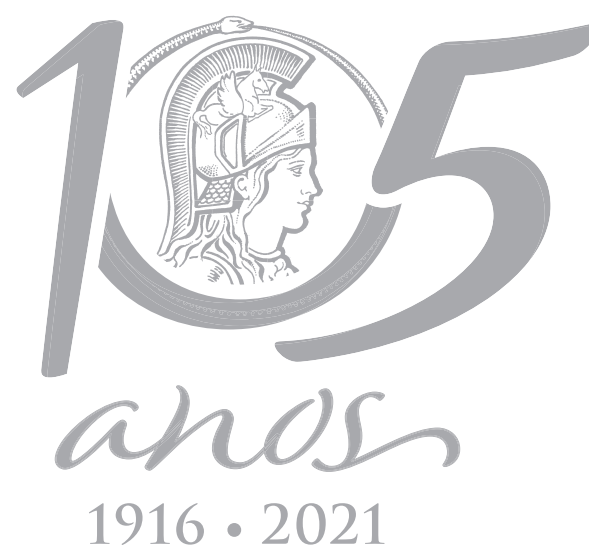

\title{
Cytogenetic approaches provide evidence of a conserved diploid number and cytological differences between Proceratophrys species (Anura: Odontophrynidae)
}

\author{
MARCELO JOÃO DA SILVA, MURILO D. SANTOS, THIAGO GAZONI, LUIZA R. \\ CHOLAK, CÉLIO FERNANDO B. HADDAD \& PATRICIA P. PARISE-MALTEMPI
}

\begin{abstract}
Taxonomic and cytogenetic aspects of Proceratophrys have not been thoroughly clarified in the literature; thus, the objective of the present study was to provide unprecedent karyotype data regarding $P$. schirchi, $P$. laticeps and P. melanopogon. Additionally, the karyotype of $P$. boiei $(2 n=22)$ and its ZZ / ZW sex chromosome system was analyzed for different populations of southeastern and southern Brazil. All Proceratophrys species have a diploid number of $2 n=22$ chromosomes. In P. schirchi, a strong C-band was found in the long arm in one of the homologues of the pair 8 in female metaphasic cells, denoting that this chromosome pair could represent the heteromorphic sex chromosome in a ZZ / ZW sex system. Despite the conserved number of chromosomes, there are considerable chromosomal differences in P. melanopogon and P. boiei (southern Brazil), strongly differentiating them cytogenetically from other species of the genus. Moreover, with the confirmation of chromosomal heteromorphism related to sexual differentiation in P. boiei and the possible description of this system in P. schirchi, the Proceratophrys genus can be regarded as an interesting group for evolutionary studies and sex chromosome differentiation in anurans.
\end{abstract}

Key words: Amphibia, C-banding, Chromosome evolution, Nucleolar organizing regions, Sex chromosomes.

\section{INTRODUCTION}

Proceratophrys is the most representative genus of the Odontophrynidae, currently comprising 41 species of small to medium-sized frogs. They are distributed from eastern to southern Brazil; northeastern Argentina and Paraguay; possibly extending into Bolivia adjacent to the Brazilian border (Frost 2021). However, the number of Proceratophrys species is probably underestimated, as indicated by the constant discovery and description of new entities (Prado \& Pombal 2008, Martins \& Giaretta 2011, 2013, Cruz et al. 2012, Brandão et al. 2013, Dias et al.
2013, Godinho et al. 2013, Mângia et al. 2014, 2018, 2020).

Based on morphological similarities, some species of Proceratophrys Miranda-Ribeiro, 1920 genus have been grouped together into different species complexes, whereas others, due to the presence of peculiar characteristics, do not belong to any group (Prado \& Pombal 2008, Amaro et al. 2009, Cruz et al. 2012, Teixeira Jr. et al. 2012, Dias et al. 2013, Mângia et al. 2018, 2020)

The $P$. boiei complex includes species that have a single long eyelid appendix without triangular rostral appendix. It includes the 
species P. boiei (Wied-Neuwied, 1824), P. paviotii Cruz, Prado and Izecksohn, 2005, and P. renalis (Miranda-Ribeiro, 1920). Species of the $P$. appendiculata complex also have single and long eyelid appendix; however, unlike the $P$. boiei group, they present a triangular rostral appendix. It includes the species $P$. appendiculata (Günther, 1873), P. belzebul Dias, Amaro, Carvahlo-e-Silva, and Rodrigues, 2013, P. gladius Mângia, Santana, Cruz, and Feio, 2014, P. itamari Mângia, Santana, Cruz, and Feio, 2014, P. izecksohni Dias, Amaro, Carvahlo-e-Silva, and Rodrigues, 2013, P. laticeps Izecksohn and Peixoto, 1981, P. mantiqueira Mângia, Santana, Cruz, and Feio, 2014, P. melanopogon (Miranda-Ribeiro, 1926), P. moehringi Weygoldt and Peixoto, 1985 , P. phyllostomus Izecksohn, Cruz and Peixoto, 1999, P. pombali Mângia, Santana, Cruz, and Feio, 2014, P. sanctaritae Cruz and Napoli, 2010 and P. subguttata Izecksohn, Cruz and Peixoto, 1999.

The species P. minuta Napoli, Cruz, Abreu and Del Grande, 2011, P. redacta Teixeira, Amaro, Recoder, Vechio and Rodrigues, 2012, P. rondonae Prado and Pombal, 2008 and P. schirchi (MirandaRibeiro, 1937) are not associated with any of these complexes due to peculiar characteristics that do not fit in any of them (Prado \& Pombal 2008, Napoli et al. 2011, Teixeira et al. 2012, Mângia et al. 2014, Frost 2021).

Recently, Mângia et al. (2020) proposed a change in the species number for the Proceratophrys cristiceps group. The authors reviewed the taxonomic status of Proceratophrys populations in the Caatinga biome based on morphological, morphometric, acoustic and multilocal genetic data, contributing to taxonomic and nomenclatural stability when describing new taxa and synonymization of other species. Without evidence supporting $P$. aridus and $P$. caramaschii as distinct species, they were characterized as junior synonyms of $P$. cristiceps (Mângia et al. 2020).
On the other hand, Magalhães et al. (2020) considered Odontophrynus salvatori Caramaschi, 1996 as belonging to the genus Proceratophrys and included this species in the $P$. cristiceps group, reinforcing the importance of several lines of evidence to avoid taxonomic instability. In this sense, cytogenetic data can provide relevant information about the chromosomal structure of taxon populations.

Cytogenetic data for Proceratophrys are restricted to the species $P$. boiei and $P$. appendiculata having a diploid number of $2 \mathrm{n}$ = 22 chromosomes (King 1990, Kuramoto 1990, Ananias et al. 2007, Amaro et al. 2012). However, P. boiei cytogenetics studies are slightly advanced in comparison to the other species. C-banding, Ag-NOR and molecular mapping of telomeric sequences were performed in the species, revealing different heterochromatin content and NOR positions between Brazilian southern and southeastern populations. Moreover, the occurrence of a ZZ / ZW sex system for this species (Ananias et al. 2007, Amaro et al. 2012, Da Silva et al. 2020) was reported. Recently, highthroughput analyzes were performed for $P$. boiei through genomic sequencing and bioinformatic analyzes, resulting in a large number of repetitive sequences isolated from its genome. Especially satellite DNAs sequences were deemed involved in heterochromatin formation and maintenance in the species (Da Silva et al. 2020).

Proceratophrys melanopogon species is distributed along Serra do Mar range in the southern, central, and northern portions of Rio de Janeiro state and in the east of São Paulo state, Brazil (Frost 2021), and is ecologically restricted to high altitude areas (Mângia et al. 2010). Proceratophrys schirchi and P. laticeps occurs in southeastern Bahia, Espírito Santo, northeastern Minas Gerais, and Rio de Janeiro (Frost 2021). Proceratophrys boiei occurs in southern Espírito Santo, southern Minas Gerais, 
in the western region of Rio de Janeiro, southern São Paulo, and from eastern Paraná to eastern Santa Catarina (Frost 2021).

Thus, considering the scarcity of cytogenetic studies on Proceratophrys in general and the increased number of newly-described species for the genus, the present study compared for the first time the chromosomes of P. melanopogon and P. laticeps (from Proceratophrys appendiculata complex), and $P$. schirchi (no defined group), increasing the number of karyotyped Proceratophys species reported in the literature. In addition, the $P$. boiei (Proceratophrys boiei group) karyotype was reevaluated, bringing new information about its chromosomal characteristics. Comparisons between already described karyotyped species were also carried out, providing relevant contributions to the understanding of chromosome evolution regarding this anuran group.

\section{Abbreviations}

NOR - Nucleolar Organizer Region;

Ag-NOR - Silver-positive NOR;

ICMBio - Chico Mendes Institute of

Biodiversity Conservation;

CEUA - Ethics Committee on Animal Use; FAPESP - Sao Paulo Research Foundation;

CAPES - Higher Education Improvement Coordination;

CNPq - National Council for Scientific and Technological Development.

\section{MATERIALS AND METHODS}

The individuals analyzed were collected in the wild under collection licenses issued by the Chico Mendes Institute for Biodiversity Conservation (ICMBio) protocol Nos. 59449 and 60972 (see Table I and Figure 1 for collection locations). The euthanasia of the specimens was performed under the consent and approval of the Ethics Committee on Animal Use - CEUA (permission 004752/2017), Biosciences Institute, UNESP, Rio Claro, SP, Brazil. The animals were deposited in the Célio F. B. Haddad (CFBH) amphibian collection, housed in the Department of Biodiversity, Biosciences Institute, UNESP, Rio Claro, SP, Brazil, except for the P. boiei species from the south of Brazil.

Metaphasic chromosomes were obtained from intestinal epithelial cells according to the protocol established by Schmid (1978), and the bone marrow and liver were collected according to Baldissera et al. (1993). The material was stained with $10 \%$ Giemsa solution, the nucleolus organizing regions (NORs) were identified through silver impregnation (Howell \& Black 1980) and constitutive heterochromatin was detected using the C-banding technique according to Sumner (1972). Giemsa-stained metaphases were photographed using an Olympus BX61 microscope and black-and-white images were recorded using a DP71 cooled digital camera. The chromosomes were ordered in decreasing size and their morphology was determined based on the metacentric, submetacentric, and subtelocentric parameters (Guerra 1986). The metaphase images were optimized in brightness and contrast using Adobe Photoshop CS6 program and arranged using Corel Draw X7 software.

\section{RESULTS}

The diploid number found for the species $P$. schirchi and $P$. laticeps was $2 n=22$ chromosomes in mitotic cells for both sexes. The karyotype of the analyzed specimens of $P$. schirchi and $P$. laticeps consisted of large- and medium-sized pairs of metacentric chromosomes $(1,6,7,8,9,10$, 
Table I. Species of Proceratophrys groups used in this study, with localizations of collected and number of species utilized. M: male; F: female.

\begin{tabular}{|c|c|c|}
\hline Species & Sex & $\begin{array}{c}\text { Collecting } \\
\text { Locations (Brazil) }\end{array}$ \\
\hline \multicolumn{3}{|c|}{ Proceratophrys appendiculata group } \\
\hline P. laticeps & $1 \mathrm{M}$ & Santa Teresa, Espírito Santo \\
\hline P. melanopogon & $1 \mathrm{M}$ & Mogi das Cruzes, São Paulo \\
\hline \multicolumn{3}{|c|}{ Proceratophrys boiei group } \\
\hline \multirow{5}{*}{ P. boiei } & $\begin{array}{l}9 \mathrm{M} \\
1 \mathrm{~F}\end{array}$ & Mogi das Cruzes, São Paulo \\
\hline & $\begin{array}{l}1 \mathrm{M} \\
5 \mathrm{~F}\end{array}$ & Camanducaia, Minas Gerais \\
\hline & $1 \mathrm{~F}$ & Tijucas do Sul, Paraná \\
\hline & $\begin{array}{l}5 \mathrm{M} \\
2 \mathrm{~F}\end{array}$ & Morretes, Paraná \\
\hline & $\begin{array}{l}2 M \\
2 F\end{array}$ & São José dos Pinhais, Paraná \\
\hline \multicolumn{3}{|c|}{ No group defined } \\
\hline P. schirchi & $\begin{array}{l}1 \mathrm{M} \\
1 \mathrm{~F}\end{array}$ & Santa Teresa, Espírito Santo \\
\hline
\end{tabular}

and 11), submetacentric chromosomes (2, 3, and 5) and a subtelocentric chromosome (4) (Fig. 2a and b). In both species, a secondary constriction was found in the short arm of chromosome pair 8, adjacent to the centromere, coincident with the NOR (Fig. 2a and b). Heterochromatin blocks were detected by $\mathrm{C}$-banding in the centromeric region of P. schirchi (Fig. 3c) and P. laticeps (Fig. 3b) chromosomes; however, in female chromosomes of $P$. schirchi, a strong C-band block on the long arm of one of the chromosomes in pair 8 was observed, indicating that this pair of chromosomes could represent a sex determination system of the ZZ / ZW type for P. schirchi (Fig. 3C, highlighted arrows).
The diploid number found in P. melanopogon was $2 n=22$ in mitotic cells, and the karyotype consisted of large- and medium-sized pairs of metacentric chromosomes $(1,6,7,8,9,10$, and 11), submetacentric chromosomes (2, 3, and 5), and a subtelocentric chromosome (4) (Fig. 2c). Unlike the other two species, in P. melanopogon a secondary constriction was found in the short arm of pair 4, where NOR is also located (Fig. 2c). Heterochromatin blocks were limited to the centromeric region of the chromosomes (Fig. 3a).

The P. boiei karyotype of the population of the Camanducaia, State of Minas Gerais, Mogi das Cruzes, state of São Paulo, and Tijucas do Sul, São José dos Pinhais, and Morretes, State 


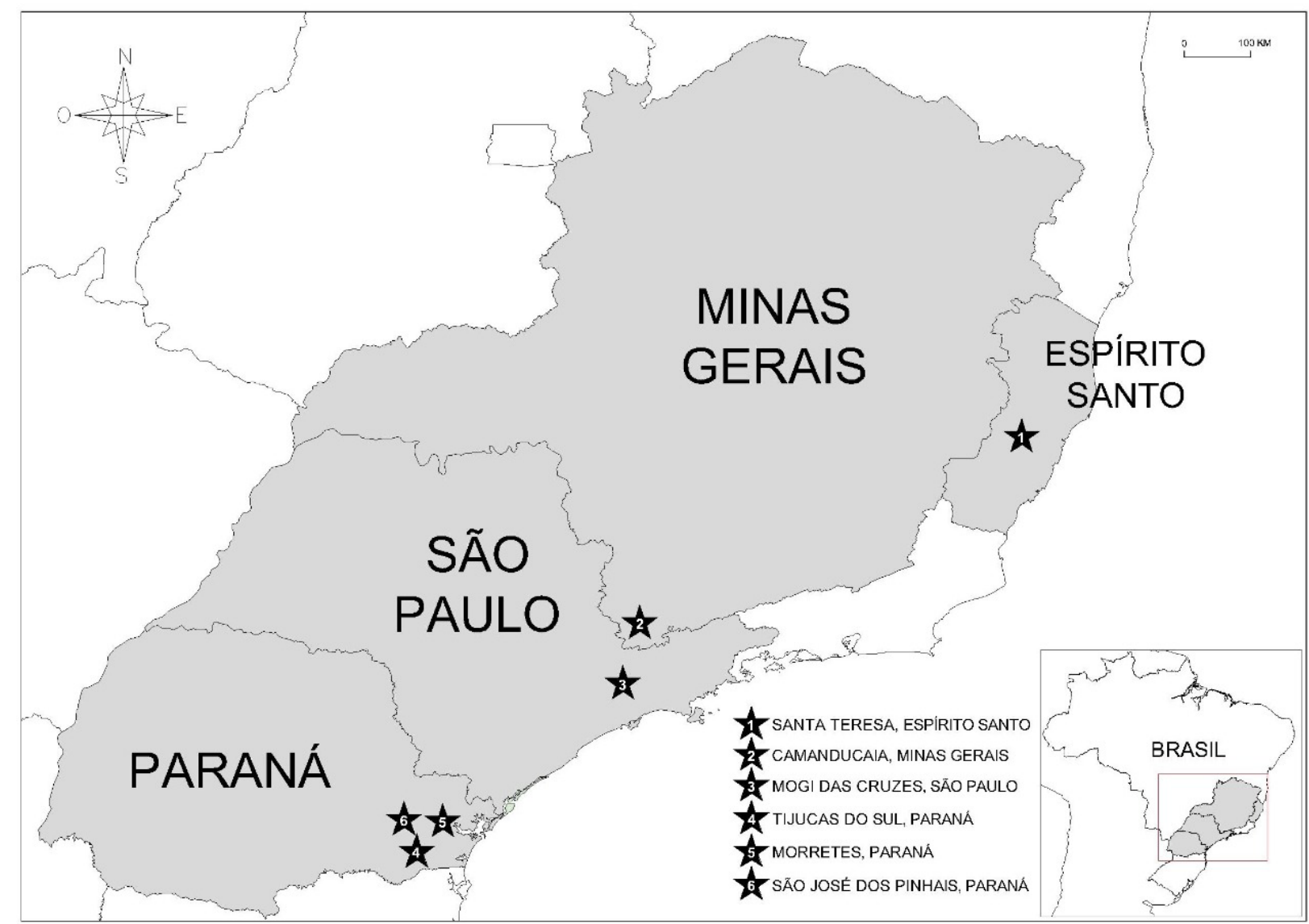

Figure 1. The collecting localities of the specimens analyzed in the present study.

of Paraná also consisted of large- and mediumsized pairs of metacentric chromosomes $(1,6,7$, $8,9,10$, and 11), submetacentric chromosomes $(2,3$, and 5$)$, and a subtelocentric chromosome (4) in both sexes (Fig. 2d and e). However, the NOR was located in the short arm of pair 8 submetacentric in an interstitial position for localities of the Southeast (Camanducaia and Mogi das Cruzes) (Fig. 2d). Differently, in the Southern localities (Tijucas do Sul, São José dos Pinhais, and Morretes) the NOR was located in the short arm of pair 4 subtelocentric in an interstitial position (Fig. 2e).

A large number of constitutive heterochromatins in the centromeric and pericentromeric regions of all the chromosomes of $P$. boiei for the localities of Southeastern Brazil was observed. In addition, the results revealed the presence of a chromosome completely heterochromatic in only one of the homologues of pair 1 in females, described as being a sexrelated chromosomal heteromorphism (Fig. 3e and $\mathrm{f}$ ). In the populations of southern Brazil, blocks of constitutive heterochromatin restricted to the centromeric region of all the chromosomes in both sexes were identified, without evidence of chromosomal heteromorphism related to sex differentiation (Fig. 3g and h).

\section{DISCUSSION}

\section{Conserved Diploid Number}

All the species analyzed in the present study have a diploid number of $2 n=22$ chromosomes, corroborating the data already described cytogenetically for P. boiei and P. appendiculata 


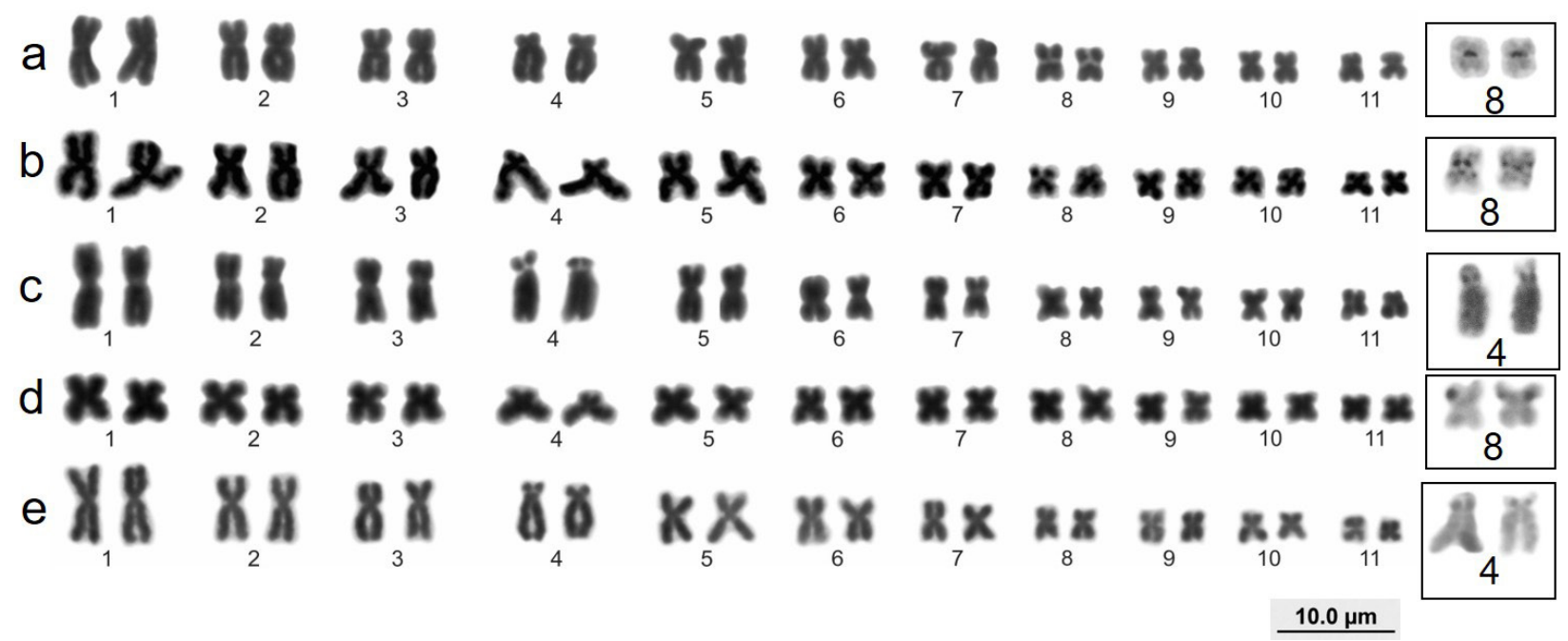

Figure 2. Karyotypes of Proceratophrys species with Giemsa-stained. a) P. schirchi (Santa Teresa, state of Espírito Santo). b) P. laticeps (Santa Teresa, state of Espírito Santo). c) P. melanopogon (Mogi das Cruzes, state of São Paulo). d) P. boiei (Camanducaia, state of Minas Gerais and Mogi das Cruzes, state of São Paulo). e) P. boiei (Tijucas do Sul, São José dos Pinhais, and Morretes, state of Paraná). Boxes refers to Nuclear Organizer Region impregnated with Silver Nitrate.

(King 1990, Ananias et al. 2007, Amaro et al. 2012). Chromosome number has already been considered as a primary difference between taxa in systematic studies of anuran amphibians, in which closely related species have more similar karyotypes than relatively distinct species (King 1990). It was possible to highlight a highly conserved karyotype, with a similar karyotype formula and differences only regarding specific interpopulation chromosome banding in $P$. boiei, without changes in the diploid number.

It is important to note that some widely distributed anuran species, like P. boiei, usually present morphological, bioacoustics, and genetic variations along their geographical distributions, which suggests that more than one taxonomic entity is being treated under one specific name. The fact that different P. boiei populations have significant cytogenetic differences was previously reported by Amaro et al. (2012) and, in the present study, with the analysis of other $P$. boiei populations, we reinforce the idea that there is a species complex under the name of
P. boiei and, therefore a thorough taxonomic revision for the genus is required.

\section{Constitutive Heterochromatin and Heteromorphic Sex Chromosomes}

The presence of heteromorphic sex chromosomes is a rare feature in anurans, and the difference between the chromosome of the sex pair is often only recognized after the use of differential staining techniques, such as C-banding, to show heterochromatic regions. To date, only $4 \%$ of the cytogenetically known species have sex chromosomes with some degree of heteromorphism (Schartl et al. 2016). Remarkably, these few species show a prevalence of larger $Y$ and $W$ chromosomes with various levels of heterochromatin accumulation (Schmid et al. 2010, Schartl et al. 2016). Nevertheless, species with either XX / XY or ZZ / ZW sex systems, and even multiple sex chromosomes have been found, presenting a Y or W chromosome with an accumulation of heterochromatin (Schmid et al. 2003, 2012, Busin et al. 2008, Nascimento et al. 2010, Schartl et al. 


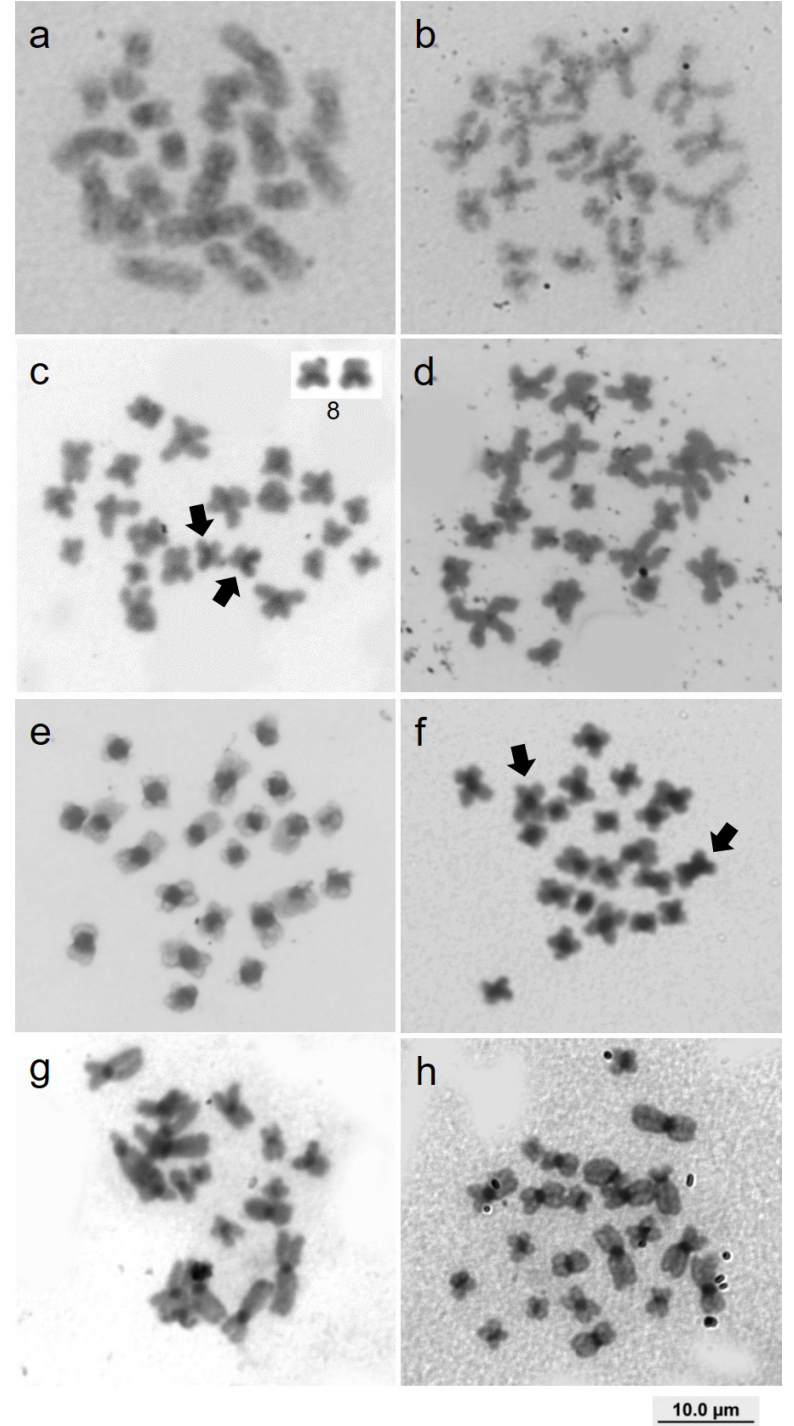

Figure 3. C-banding in Proceratophrys species. a) $P$. melanopogon (Mogi das Cruzes, state of São Paulo). b) $P$. laticeps (Santa Teresa, state of Espírito Santo). c) P. schirchi (Santa Teresa, state of Espírito Santo) female, and d) P. schirchi male. e) and f) P. boiei (Female and Male, respectively) (Camanducaia, state of Minas Gerias and Mogi das Cruzes, state of São Paulo). g) and h) P. boiei (Female and Male, respectively) (Tijucas do Sul, São José dos Pinhais, and Morretes, state of Paraná). The box in c) and the arrows in f) indicate the heteromorphic sex chromosomes in P. schirchi (pair 8) and $P$. boiei (pair 1 ), respectively.

2016, Gatto et al. 2016, Gazoni et al. 2018, Da Silva et al. 2020).

Interpopulation analysis of $P$. boiei specimens from the southeastern and northeastern of Brazil revealed unusual heterochromatic patterns between populations (Ananias et al. 2007). Populations of P. boiei of the southeast have large centromeric and pericentromeric heterochromatic blocks, while samples from the northeast did not present these features. In addition, females from São Paulo State (southeast) have a large heterochromatic block in one of the homologous of the chromosomal pair 1, while males have heterochromatin restricted to the centromeric region in both chromosomes. This unusual heterochromatic arrangement led Ananias et al. (2007) to propose a ZZ / ZW sex system for $P$. boiei, the first occurrence registered within Odontophrynidae. The same chromosomal heteromorphism was detected in individuals of other locations within the geographical range of the state of São Paulo, the ZZ / ZW sex chromosome system seems to be generalized in P. boiei (Amaro et al. 2012, Da Silva et al. 2020).

This karyotypic composition for P. boiei was confirmed in the present study for the sample of Mogi das Cruzes (São Paulo state) and Camanducaia (Minas Gerais state), in which the chromosomal set of the analyzed specimens are also heteromorphic in females, further highlighting the generalization of chromosomal heteromorphism related to sex in P. boiei. However, for populations of $P$. boiei from southern Brazil analyzed in this work, a completely different pattern from that observed in southeastern populations was found especially regarding the size and number of heterochromatic blocks and the presence of chromosomal heteromorphism related to sexual differentiation.

In the analyzed P. boiei individuals, the positive $\mathrm{C}$-band regions were limited to the centromeric region and none showed heteromorphic chromosomes. This pattern has already been described by Amaro et al. (2012); 
however, for populations from the south of São Paulo (southeastern Brazil) and one from Santa Catarina (southern Brazil). In this work, samples of $P$. boiei from southern populations in Brazil were analyzed and the results revealed the same distribution pattern of constitutive heterochromatin, restricted to the centromeric region, suggesting that this feature is consolidated in all P. boiei samples from the southern region.

Intraspecific variation in C-band pattern can be found, for example, among distinct populations of the same species (Amaro-Ghilardi et al. 2004, Silva et al. 2004), as in P. boiei (Amaro et al. 2012). For the Proceratophrys species analyzed in the present study, there were no interstitial and terminal markings, except for the unusual pattern already described for P. boiei and, in this sense, C-bands can be potentially used to identify species in this genus, and more studies based in this technique must be performed within Proceratophrys.

The results provide the first description of C-banding in P. schirchi, P. laticeps, and P. melanopogon, which showed C-positive bands predominantly located as discrete blocks in the centromeric region of the chromosomes. However, differently from $P$. laticeps and $P$. melanopogon, the P. shirchi female analyzed here presents a homologous chromosome with a large heterochromatic block throughout the long arm (pair 8), which not present in male chromosomes, leading us to think of the presence of ZZ / ZW sex system in this species. Sex-related heteromorphism following C-banding treatment has been reported in anurans (Ananias et al. 2007, Busin et al. 2008, Nascimento et al. 2010) and it is interesting to note that in some cases of sexual differentiation in amphibians, the $\mathrm{W}$ chromosome may be completely or partially heterochromatic. The putative distinct ZZ / ZW sex system in $P$. schirchi, reinforces the idea that heterochromatinization is a process that precedes the morphological differentiation of $W$ and $Y$ chromosomes, and that the stages of morphological differentiation of sex chromosomes in anuran species is important not only for amphibian cytogenetics but also for understanding the evolution of vertebrate sex chromosomes as a whole (Ananias et al. 2007).

\section{Nucleolar organizer regions (NORs)}

Despite the conserved diploid number in Proceratophrys, a difference in chromosomal formula was observed in P. melanopogon. An atypical secondary constriction was found in the interstitial position on the short arm of pair 4 , differing from P. schirchi, P. laticeps, and P. boiei, whose constriction is in pair 8. Coincidentally, in P. melanopogon the NOR was located next to the secondary constriction found in this species. However, P. boiei (populations from southeastern Brazil) also showed NOR located in pair 8; however, but for the southern populations, it was present in pair 4, revealing that the different locations of NORs in this species may further contribute to characterize populations and provide relevant information for taxonomic studies. Ananias et al. (2007) found heteromorphic NORs in chromosomal pair 8 in two $P$. boiei specimens from Mata de São João, State of Bahia, Brazil, a fact that reinforces this location and position of NORs in $P$. schirchi and P. laticeps. However, we found a different position in P. melanopogon and P. boiei (Southern populations) in the present work, despite the fact that these are closely related species.

The NOR could appear either in the short arms, in the long arms, in the terminal, distal, interstitial, or proximal positions. However, it may occur in other chromosomal pairs, as observed for P. melanopogon and P. boiei (southern populations), where the NOR was presented 
in pair 4. This result suggests that micro rearrangements such as deletion/duplication of chromosomal segments or inversions may have occurred independently in this species. In this sense, a case of multiple NOR was reported for P. boiei from a population of Iperó, São Paulo, where an individual showed a standard NOR for the species in pair 8 and another NOR in pair 4 (Amaro et al. 2012), further reinforcing that chromosomal rearrangements have been occurring independently of the Proceratophrys species.

The results provided by the present study increase the number of species with known karyotypes in Proceratophrys and include the first karyotype description for P. schirchi, P. laticeps, and P. melanopogon, contributing to a better understanding of chromosomal evolution and providing input for future taxonomic and cytogenetic studies in this group of anurans. Although there is a conserved pattern related to the number of chromosomes, there are considerable chromosomal differences in $P$. melanopogon and P. boiei (southern Brazilian populations), substantially differentiating them from the other species. Moreover, with the confirmation of chromosomal heteromorphism related to sexual differentiation in $P$. boiei and the possible description of this system in $P$. schirchi, the Proceratophrys genus could be considered an interesting group for studies on the evolution and differentiation of sexual chromosomes.

\section{Acknowledgments}

The authors are grateful to Prof. Dr. Sanae Kasahara (in memorian) for providing part of cytogenetic material used in this work. We are also grateful to colleagues Hideki Narimatsu and Paulo Sérgio Pereira dos Santos for their help in specimen collection, to Prof. Dr. Daniel Pacheco Bruschi for kindly preparing cytogenetic material from P. boiei of South populations, to MSC. Carolina Crepaldi for the help in revising the manuscript and to Adalberto Mota Silva de Oliveira for his help with making the species location map. This research was supported by Sao Paulo Research Foundation (FAPESP \#2017/00195_7). Studentship was granted by Coordenação de Aperfeiçoamento de Pessoal de Nivel Superior (CAPES) - Financing code 001. CFBH is grateful to Conselho Nacional de Desenvolvimento Científico e Tecnológico (CNPq) for the research fellowship (306623/2018-8), and FAPESP, for the financial support (\#2013/50741-7). The authors declare no competing interests.

\section{REFERENCES}

AMARO RC, RODRIGUES MT, YONENAGA-YASSUDA Y \& CARNAVAL ACQ. 2012. Demographic process in montane Atlantic rainforest: Molecular and cytogenetic evidence from the endemic frog Proceratophrys boiei. Mol Phylogenet Evol 62: 880-888

AMARO RC, PAVAN D \& RODRIGUES MT. 2009. On the generic identity of Odontophrynus moratoi Jim \& Caramaschi, 1980 (Anura, Cycloramphidae). Zootaxa 2071: 61-68.

AMARO-GHILARDI RC, RODRIGUES MT \& YONENAGA-YASSUDA Y. 2004. Chromosomal studies after differential staining and fluorescence in situ hybridization using telomeric probe in three Leptodactylus species (Leptodactylidae, Anura). Caryologia 57: 53-65.

ANANIAS F, MODESTO ADS, MENDES SC \& NAPOLI MF. 2007. Unusual primitive heteromorphic ZZ/ZW sex chromosomes in Proceratophrys boiei (Anura, Cycloramphidae, Alsodinae), with description of C-Band interpopulational polymorphism. Hereditas 144: 206-212.

BALDISSERA FA, OLIVEIRA PSL \& KASAHARA S. 1993. Cytogenetics of four Brazilian Hyla species (AmphibiaAnura) and description of a case with a supernumerary chromosome. Rev Bras Genet 16: 335-345.

BRANDÃO RA, CARAMASCHI U, VAZ-SILVA W \& CAMPOS LA. 2013. Three new species of Proceratophrys Miranda-Ribeiro 1920 from Brazilian Cerrado (Anura, Odontophrynidae). Zootaxa 3750: 321-347.

BUSIN CS, ANDRADE GV, BERTOLDO J, DEL GRANDE ML, UETANABARO M \& RECCO-PIMENTEL SM. 2008. Cytogenetic analysis of four species of Pseudis (Anura, Hylidae), with the description of ZZ/ZW sex chromosomes in $P$. tocantins. Genetica 133: 119-127.

CRUZ CAG, NUNES I \& JUNCÁ FA. 2012. Redescription of Proceratophrys cristiceps (Müller, 1883) (Amphibia, Anura, Odontophrynidae), with description of two new 
species without eyelid appendages from Northeatern Brazil. South Am J Herpetol 7: 110-122.

DA SILVA MJ, DESTRO RF, GAZONI T, NARIMATSU H, SANTOS PSP, HADDAD CFB \& PARISE-MALTEMPI PP. 2020. Great Abundance of Satellite DNA in Proceratophrys (Anura, Odontophrynidae) Revealed by Genome Sequencing. Cytogenet Genome Res 160: 141-147.

DIAS PHS, AMARO RC, DE CARVALHO-E-SILVA AMPT \& RODRIGUES MT. 2013. Two new species of Proceratophrys MirandaRibeiro, 1920 (Anura; Odontophrynidae) from the Atlantic forest, with taxonomic remarks on the genus. Zootaxa 3682: 277-304.

FROST DR. 2021. Amphibian Species of the World: an Online Reference. Version 6.0 (06 fev. 2021). Electronic Database accessible at http://research.amnh.org/ herpetology/amphibia/index.html. American Museum of Natural History, New York, USA.

GATTO KP, BUSIN CS \& LOURENÇO LB. 2016. Unraveling the sex chromosome heteromorphism of the paradoxical frog Pseudis tocantins. PLoS One 11(5): e0156176.

GAZONI T, HADDAD CFB, NARIMATSU H, CABRAL-DE-MELLO DC, LYRA ML \& PARISE-MALTEMPI PP. 2018. More sex than autosomes in the Amazonian frog Leptodactylus pentadactylus. Chromosoma 127: 269-278.

GODINHO LB, MOURA MR, LACERDA JVA \& FEIO RN. 2013. A new species of Proceratophrys (Anura: Odontophrynidae) from the middle São Francisco River, southeastern Brazil. Salamandra 49: 63-73.

GUERRA MS. 1986. Reviewing the chromosome nomenclature of Levan et al. Rev Bras Genet 9(4): 741-743.

HOWELL WM \& BLACK DA. 1980. Controlled silver staining of the nucleolus organizer regions with a protective colloidal developer: a 1-step method. Experientia 36: 1014-1015.

KING M. 1990. Amphibia. In: John, B. Animal Cytogenetics. Amphibia, 4. Chordata 2. Berlin: Gebrüder Borntraeger.

KURAMOTO M. 1990. A list of chromosome numbers of anuran amphibians. Bulletin of Fukuoka University of Education 39: 83-127.

MAGALHÃES FM, BRANDÃO RA, GARDA AA \& MÂNGIA S. 2020. Revisiting the generic position and acoustic diagnosis of Odontophrynus salvatori (Anura: Odontophrynidae). Herpetol J 30: 189-196.

MÂNGIA S, SANTANA DJ \& FEIO RN. 2010. Advertisement call of the Cycloramphidae toad Proceratophrys melanopogon (Miranda-Ribeiro, 1926). South Am J Herpetol 5: 127-131.
MÂNGIA S, KOROIVA R, NUNES PMS, ROBERTO IJ, ÁVILA RW, SANT'ANNA AC, SANTANA DJ \& GARDA AA. 2018. A new species of Proceratophrys (Amphibia: Anura: Odontophrynidae) from the Araripe Plateau, Ceará State, northeastern Brazil. Herpetologica 74: 255-268.

MÂNGIA S, SANTANA DJ, CRUZ CAG \& FEIO RN. 2014. Taxonomic review of Proceratophrys melanopogon (Miranda Ribeiro, 1926) with description of four new species (Amphibia, Anura, Odontophrynidae). Boletim do Museu Nacional 531: 1-33.

MÂNGIA S, OLIVEIRA EF, SANTANA DJ, KOROIVA R, PAIVA F \& GARDA AA. 2020. Revising the taxonomy of Proceratophrys Miranda-Ribeiro, 1920 (Anura: Odontophrynidae) from the Brazilian semiarid Caatinga: Morphology, calls and molecules support a single widespread species. J Zool Syst Evol Res 58(4): 1151-1172.

MARTINS LB \& GIARETTA AA. 2011. A new species of Proceratophrys Miranda-Ribeiro (Amphibia: Anura: Cycloramphidae) from central Brazil. Zootaxa 2880: 41-50.

MARTINS LB \& GIARETTA AA. 2013. Morphological and acoustic characterization of Proceratophrys goyana (Lissamphibia: Anura: Odontophrynidae), with the description of a sympatric and related new species. Zootaxa 3750: 301-320.

NAPOLI MF, CRUZ CAG, DE ABREU RO \& DEL-GRANDE ML. 2011. A new species of Proceratophrys Miranda-Ribeiro (Amphibia: Anura: Cycloramphidae) from the Chapada Diamantina, State of Bahia, northeastern Brazil. Zootaxa 3133: 37-49.

NASCIMENTO J, QUINDERÉ YRSD, RECCO-PIMENTEL SM, LIMA JRF \& LOURENÇO LB. 2010. Heteromorphic Z and $W$ sex chromosomes in Physalaemus ephippifer (Steindachner,1864) (Anura, Leiuperidae). Genetica 138: 1127-1132.

PRADO GM \& POMBAL JP. 2008. Espécies de Proceratophrys Miranda-Ribeiro, 1920 com apêndices palpebrais (Anura; Cycloramphidae). Arquivos de Zoologia 39: 1-85.

SCHARTL M, SCHMID M \& NANDA I. 2016. Dynamics of vertebrate sex chromosome evolution: from equal size to giants and dwarfs. Chromosoma 125: 553-571.

SCHMID M. 1978. Chromosome banding in Amphibia I: constitutive heterochromatin and nucleolus organizer regions in Bufo and Hyla. Chromosoma 66: 361-388.

SCHMID M, STEINLEIN C, BOGART JP, FEICHTINGER W, LEÓN P, LA MARCA E, DÍAZ LM, SANZ A, CHEN S-H \& HEDGES SB. 2010. The chromosomes of Terraranan frogs: insights into vertebrate cytogenetics. Cytogenet Genome Res 130-131: $1-14$. 
SCHMID M, FEICHTINGER W, STEINLEIN C, VISBAL-GARCÍA R \& FERNÁNDEZ-BADILLO A. 2003. Chromosome banding in Amphibia. XXVIII. Homomorphic XY sex chromosomes and a derived $Y$-autosome translocation in Eleutherodactylus riveroi (Anura, Leptodactylidae). Cytogenet Genome Res 101: 62-73.

SCHMID M, STEINLEIN C, BOGART JP, FEICHTINGER W, HAAF T, NANDA I, DEL PINO EM, DUELLMAN WE \& HEDGES SB. 2012. The hemiphractid frogs. Phylogeny, embryology, life history, and cytogenetics. Cytogenet Genome Res 138: 69-384.

SILVA APZ, GARCIA PCA, MARTINS VG, BACCI M \& KASAHARA S. 2004. Chromosomal and molecular analyses of Leptodactylus gracilis gracilis, L. gracilis delattini, and L. plaumanni (Anura, Leptodactylidae): taxonomic implications. Amphibia-Reptilia 25: 185-196.

SUMNER AT. 1972. A simple technique for demonstrating centromeric heterochromatin. Exp Cell Res 75: 304-306.

TEIXEIRA M, AMARO RC, RECODER RS, DAL VECHIO F \& RODRIGUES MT. 2012. A new dwarf species of Proceratophrys MirandaRibeiro, 1920 (Anura, Cycloramphidae) from highlands of Chapada Diamantina, Bahia, Brazil. Zootaxa 3551: 25-42.

\section{How to cite}

SILVA MJ, SANTOS MD, GAZONI T, CHOLAK LR, HADDAD CFB \& PARISEMALTEMPI PP. 2021. Cytogenetic approaches provide evidence of a conserved diploid number and cytological differences between Proceratophrys species (Anura: Odontophrynidae). An Acad Bras Cienc 93: e20201650. DOI 10.1590/0001-3765202120201650.

Manuscript received on October 19, 2020;

accepted for publication on February 17, 2021

\section{MARCELO JOÃO DA SILVA}

https://orcid.org/0000-0001-5169-4100

\section{MURILO D. SANTOS ${ }^{1}$}

https://orcid.org/0000-0002-3478-8890

\section{THIAGO GAZONI ${ }^{1}$}

https://orcid.org/0000-0001-5068-3143

\section{LUIZA R. CHOLAK'}

https://orcid.org/0000-0002-1759-9828

\section{CÉLIO FERNANDO B. HADDAD ${ }^{2}$}

https://orcid.org/0000-0002-7044-5764

\section{PATRICIA P. PARISE-MALTEMPI ${ }^{1}$}

https://orcid.org/0000-0001-7414-9463

${ }^{1}$ Universidade Estadual Paulista, Departamento de Biologia Geral e Aplicada, Instituto de Biociências, Avenida 24A, 1515, Bela Vista, 13506-900 Rio Claro, SP, Brazil

${ }^{2}$ Universidade Estadual Paulista, Departamento de Biodiversidade e Centro de Aquicultura, Instituto de Biociências, Avenida 24A, 1515, Bela Vista, 13506-906 Rio Claro, SP, Brazil

\section{Correspondence to: Patricia Pasquali Parise-Maltempi}

E-mail: patricia.parise@unesp.br

\section{Author contributions}

MJS analyzed the data and wrote the manuscript. MJS, MDS, TG and LRC conducted the classic cytogenetic analyses. MJS, TG, LRC and CFBH collected the specimens. CFBH identified the specimens. PPPM coordinated the research and revised the manuscript. All authors corrected, revised and discussed the data.

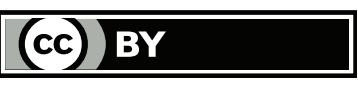

